\title{
Influence on indoor comfort due to the application of Covid-19 natural ventilation protocols for schools at subtropical climate during winter season
}

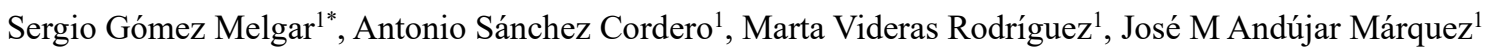 \\ ${ }^{1}$ TEP192 Control y Robótica, Escuela Técnica Superior de Ingeniería, Universidad de Huelva, CP. 21007 Huelva, Spain.
}

\begin{abstract}
Thermal comfort and energy performance of our buildings has been seriously improved during the last decades with the introduction of better envelope airtightness and mechanical ventilation systems. The arrival of Covid-19 has forced us to accept new natural ventilation protocols to improve the air quality inside buildings over other characteristics of the buildings. As a consequence, it brings some negative effects, like a reduction in the control of indoor dry bulb temperature $(\mathrm{T})$, and an increase in energy demand for heating and air conditioning. To evaluate these influences during a winter season, a standard classroom from a school located at subtropical climate has been selected to be monitored with air quality and comfort devices. The experiment considers two different scenarios in 2018, and 2021. At them, data have been compared with several comfort ranges from international standards and the recommendations from the Spanish Government, obtaining opposite results. The results from 2018 showed that the comfort $\mathrm{T}$ ranges were adequate, but $\mathrm{CO}_{2}$ concentrations rise over 2000 ppm which was unhealthy. On the contrary, in 2021 when the Covid-19 natural ventilation protocol is activated, the $\mathrm{CO}_{2}$ concentration becomes less than $700 \mathrm{ppm}$. Finally, the suggested natural ventilation protocol was proved as an efficient measure to improve air quality, but it reduces the performance of the building in terms of comfort and energy demand. Therefore, several alternative ventilation methods should be considered to keep both energy air quality building's performance.
\end{abstract}

\section{Introduction}

Children spend inside schools an important part of their lives, and many often, the comfort conditions of these buildings seem to be inconvenient. Many assessment methods have been recently released to provide comprehensive evaluations about comfort and social sustainability inside buildings [1]. Even in many modern countries, most of the schools are old, poorly insulated, and with phase out facilities [2]-[4]. Therefore, parameters such as energy performance, air quality, $\mathrm{T}$ and relative humidity stay far from those suggested in best practices guides in most of the cases. Several studies have reviewed the indoor conditions of schools and kindergarten with unsatisfactory conclusions [2], [6].

In some cases, indoor air quality may be improved with natural ventilation, but some problems may arise in those schools located in polluted environments. There, ventilation has to be carefully considered in combination with filtering and mechanical systems [7]-[9].

Since the recent spread of the disease Covid-19, the improvement of air quality has appeared with more relevance than before. It is now a matter of fact that Covid19 is mainly spread by airborne transmission [10], [11]. Unfortunately, there are no efficient methodologies to measure the concentration of Covid-19 in the air now. However, some alternative methodologies can be applied to approximate the idea of infection risk looking at the concentration of $\mathrm{CO} 2$ in the air. Additionally, it has been proved as an easy and cheap method to measure the indoor air quality [12]. Because of the proved relationship between Covid-19 and the $\mathrm{CO} 2$, decision makers has set regulations to increase natural ventilation as the best option to reduce Covid-19 indoor airborne transmission [13]. In particular, the Spanish government set some ventilation protocols that should be considered in all buildings, but specifically in those for education [14]. These protocols stablish the need to maintain natural ventilation during all the time children are inside the classroom. They set $12.5 \mathrm{l} / \mathrm{sec}$ per person as the minimum exterior air renovation [15], but recognize that some problems may arise with extreme $\mathrm{T}$ in winter and summer. The effectiveness of this ventilation protocol can be evaluated using $\mathrm{CO}_{2}$ measuring devices.

Unfortunately, the generalized use of exterior air for natural ventilation can lead to comfort problems, such as noise, pollution, exposure to wind gust, inadequate relative humidity, but most important uncomfortable $\mathrm{T}$ [16]. Additionally, this ventilation protocol is producing extra energy demand for the heating, ventilation, and air conditioning (HVAC) systems. Obviously, these effects vary depending on the climate of the site, and it may be less important in warm subtropical climates than others [17].

Correspondence author: sergomel@uhu.es 
This paper aims to compare the performance of the air quality and comfort parameters between 2 different scenarios: the first one with free natural ventilation with openings controlled by teachers according to their comfort experience, whilst the second provides natural ventilation during all time the time scholars are inside the room. Finally, some improvements to the current ventilation protocol can be suggested to increased comfort, that would probably reduce HVAC primary energy demand.

\section{Material and Method}

\subsection{Case study}

The classroom monitored is in a public school in the city center of Sevilla (Spain) at 37.39 north latitude, and 5.98 east longitude. Figure 1, shows the aerial view with the north-south orientation, with the classroom position marked in red. The original building was built in 1946, and since then it was enlarged and modified several times according to the evolution of the educational trends. The envelope of the building is poorly insulated. The HVAC system is based: a central controlled system with high temperature hot water radiators for winter conditions, and a decentralized air condition with air-to-air split units for summer conditions. There is no mechanical ventilation system for air renovation.

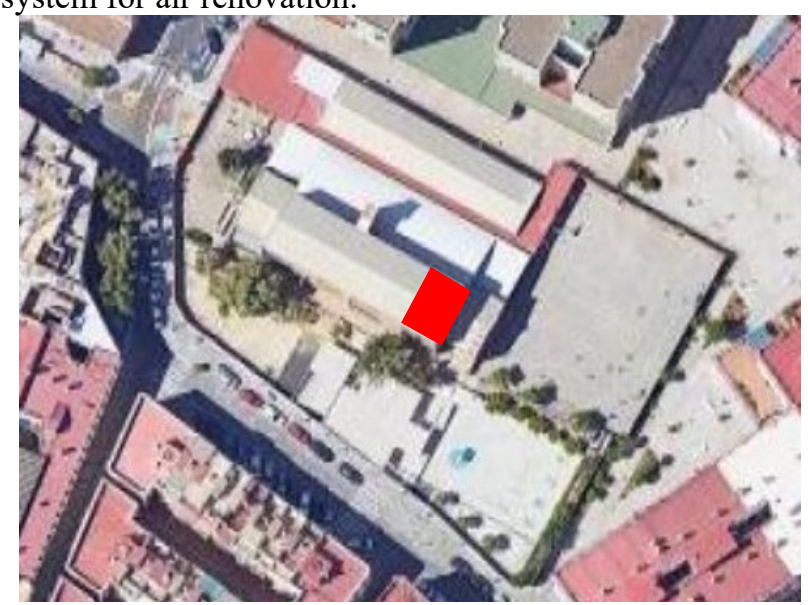

Figure 1. Aerial view, Google [18]

Figure 2. shows the studied classroom within the building from the north east view

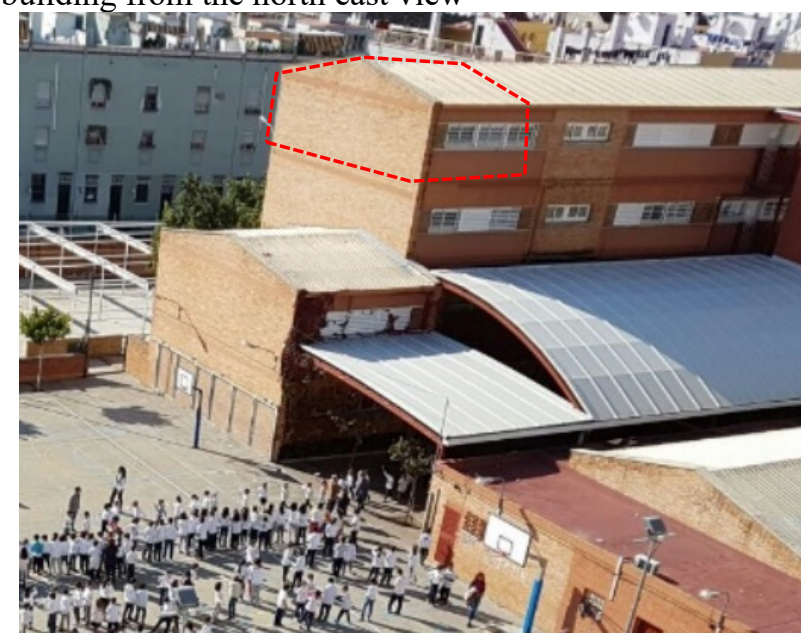

Figure 2. South east bird view
.Figure 3 describes the geometry and the specific position of openings, HVAC systems, and monitoring devices. The size of the room is $8.0 \times 6.2 \times 3.7 \mathrm{~m}^{3}$. Windows are located at south and north facades, providing full cross ventilation. The facade includes a set of white louvres to reduce solar radiation in the cooling season. The radiators (in red color) are located at the north façade, under the windows. The AC system (in blue color) is in the south east corner, see Figure 3.

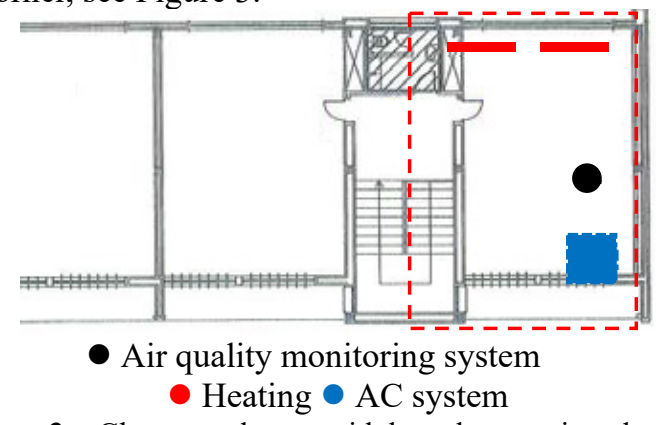

Figure 3. Classroom layout with key elements in colour.

\subsection{Materials and Method}

According to Figure 3 the air quality monitoring systems (in black color) were located at the east facade at $0.9 \mathrm{~m}$ above de floor. Figure 4 shows the position of the devices. All children in the classroom look at the opposite direction to reduce the unwanted effect of close breathing. The position of the devices is also intentionally separated from windows to reduce the local effect of the openings.

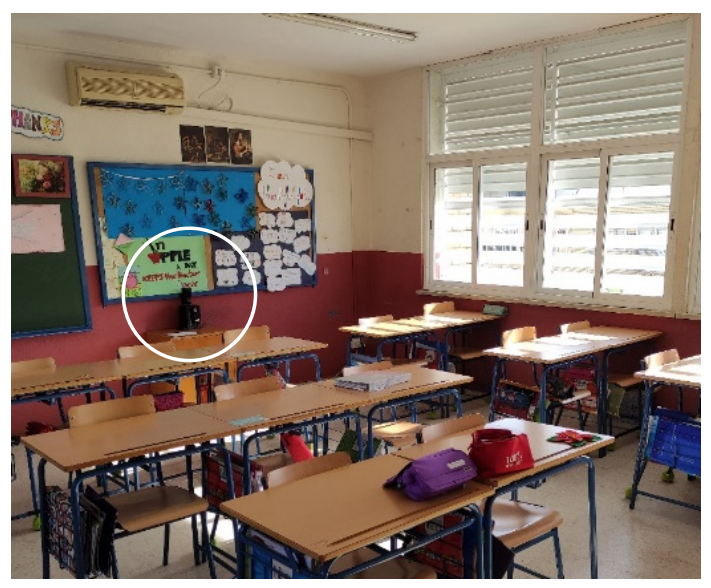

Figure 4. Classroom view.

Figure 5 shows the devices located at the back of the classroom. Described as " 1 ", the device installed in 2017 , set by the University of Burgos [4]. It measures and record $\mathrm{T}$ in ${ }^{\circ} \mathrm{C}, \mathrm{RH}$ in $\%$ and $\mathrm{CO}_{2}$ in ppm every 10 minutes. However, at the end of 2020, another device described as "2" in Figure 5, the EGVOC-165 Air quality Monitor with a NDIR $\mathrm{CO}_{2}$ sensor was installed to provide remote access. It measured several parameters, including $\mathrm{T}, \mathrm{RH}$ and $\mathrm{CO}_{2}$ concentration, every $1.5 \mathrm{sec}$. The " 2 " device was connected to a mobile WIFI system: 4G LTE M7200 from tp-link, described as " 3 " in Figure 5. 


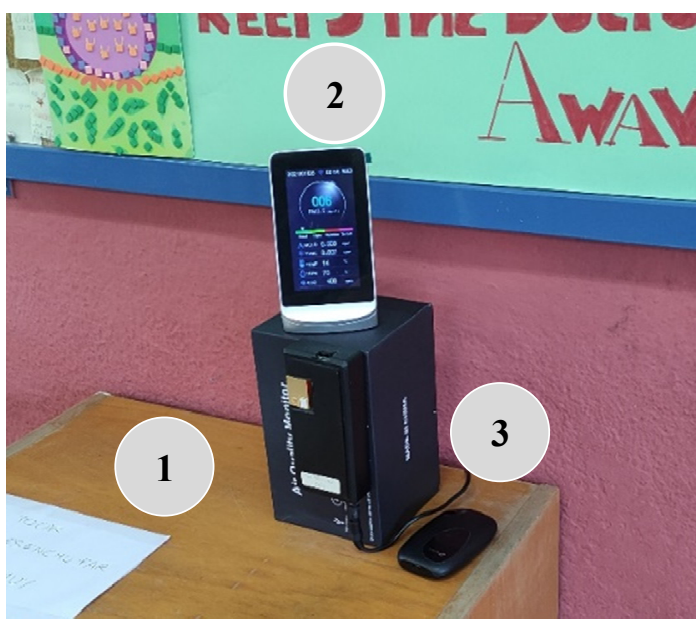

Figure 5. Monitoring devices "1, 2, 3"

Climate data have been obtained from a close weather station registered in Weather Underground [19] and collected manually on the $26^{\text {th }}$ of January 2021 .

With all data collected from both scenarios: 2018, and 2021, results graphs have been obtained and compared with those comfort ranges suggested by the literature review. Air quality and $\mathrm{CO}_{2}$ concentration in ppm, have been compared with $800 \mathrm{ppm}$ as the highest recommendable value to reduce Covid-19 airborne infection as the Spanish government has set [14]. Temperature comfort ranges have been defined according to methodology defined in ASHRAE 55_2017 (see equations (1), (2) and (3)) for all buildings and based in the concepts of adaptivity and $80 \%$ of acceptability [20]. The mean outdoor temperature used for calculations has been set by the average between 2018 and 2021 .

$$
T c=(17.6+0.31 T o)
$$

Considering the $80 \%$ of acceptability

$$
\begin{aligned}
T c 1 & =(T c-2.5) \\
\text { and } T c 2 & =(T c+2.5)
\end{aligned}
$$

\section{Results}

At any regular day of both scenarios, the heating system worked from 08:00 to 14:00, whilst the children stayed at school from 09:10 to $13: 45$, but with a short recess from $11: 30$ to $12: 00$, see Figure 6.

On the contrary, natural ventilation was different in 2021 from 2018. According to Covid-19 ventilation protocol, the natural ventilation is working from 09:10, when the children get in the classroom, until 14:00, when they leave (see Figure 6). There is no strict evidence about the ventilation proceeding in 2018, but according to teacher's survey, most of the time the openings were close at that time and they freely operate depending on their comfort perception.

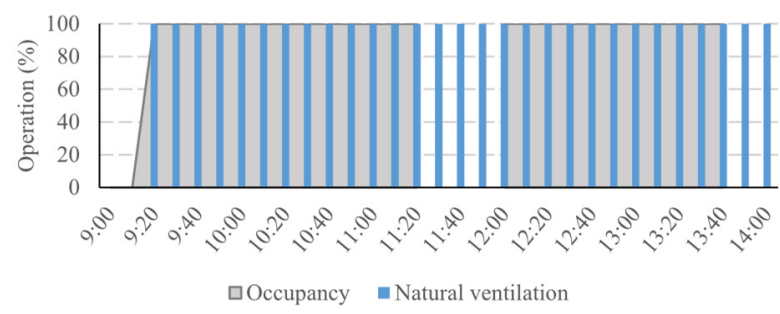

Figure 6. Operation schedule in a 2021 typical winter day.

\subsection{Air quality}

Air quality data is shown in Figures 6 and 7 The data have been obtained from one typical winter day in January. Figure 6 contains 2018 data, whilst Figure 3. contains 2021 data. Graphs in Figure 7 and 3.3 contain $\mathrm{CO}_{2}$ concentration in ppm compared with those security limits set by other authors: 800 ppm for Covid-19 security protocols, and $1000 \mathrm{ppm}$ according to ASHRAE 62.1 recommendations [21].

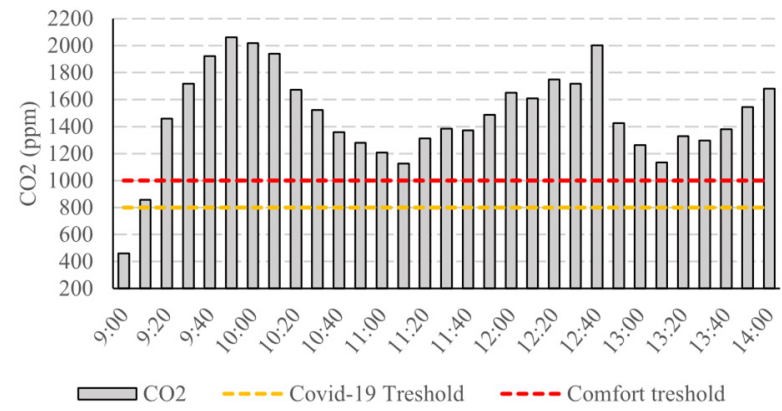

Figure 7. $\mathrm{CO}_{2} \mathrm{ppm}$ in a typical winter day, 26th January2018.

According to Figure 7, data from 2018 were as follows: at 09:00 the $\mathrm{CO}_{2}$ was $460 \mathrm{ppm}$, but as soon as the children arrived to the room it started to rise rapidly until $2061 \mathrm{ppm}$ at 09:50. Since 10:00, the $\mathrm{CO}_{2}$ was reduced until 1125 ppm at 11:10. When the children came back from the break time at 12:00, the $\mathrm{CO}_{2}$ concentration was 1649 ppm, and it kept rising until $2002 \mathrm{ppm}$ at 12:40. Since then, the $\mathrm{CO}_{2}$ started to decrease to $1133 \mathrm{ppm}$ at 13:10. Finally, the $\mathrm{CO}_{2}$ increased again until $1681 \mathrm{ppm}$ at 14:00. According to these data, the $\mathrm{CO}_{2}$ levels stayed over security levels for all the considered time, except from at 09:10 when children arrived at the classroom.

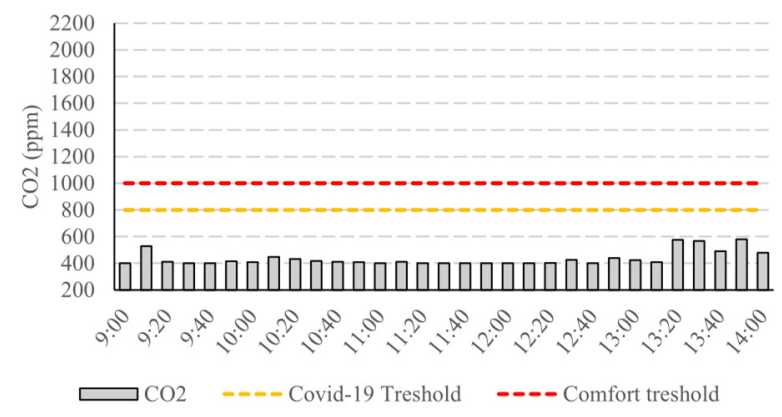

Figure 8. $\mathrm{CO}_{2} \mathrm{ppm}$ in a typical winter day, 26th January 2021

Figure 8 shows data from 2021 as follows: at 09:00 the $\mathrm{CO}_{2}$ was $400 \mathrm{ppm}$ or less and it remained under $500 \mathrm{ppm}$ until 13:20, and always under $600 \mathrm{ppm}$. Therefore, the concentration of $\mathrm{CO}_{2}$ remained always under security 
limits when the openings in the classroom were fully open during all the morning.

\subsection{Temperature \& comfort}

$\mathrm{T}$ and adaptive $\mathrm{T}$ comfort ranges are shown in Figures 9 and 10 for the selected typical winter days in January 2018 and 2021. The $\mathrm{T}$ comfort ranges have been set into $18.4^{\circ} \mathrm{C}$ and $23.1^{\circ} \mathrm{C}$ for both scenarios.

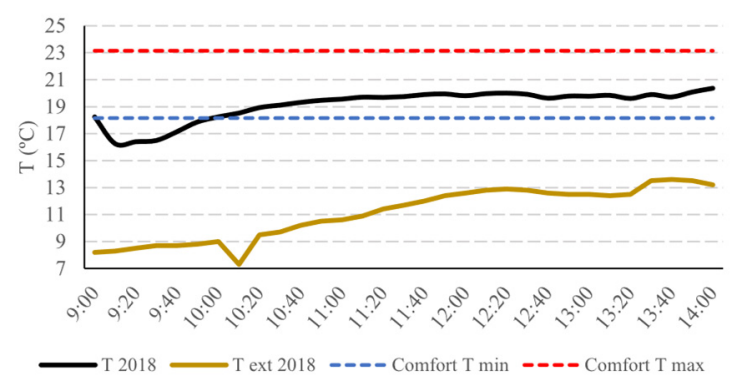

Figure 9. $\mathrm{T}^{\circ} \mathrm{C}$ in a typical winter day, 26th January 2018 , compared with adaptative ASHRAE comfort range

As seen in Figure 9, in 2018, at 09:00 T was $18^{\circ} \mathrm{C}$, but it decreased fast until $16^{\circ} \mathrm{C}$ at 09:20 when doors got open. Since then, the T increased steadily until $20^{\circ} \mathrm{C}$ at $11: 50$ and it remain with small variations until the end of the studied period at 14:00. Therefore, the T stayed between comfort conditions from 10:00, whilst the exterior $\mathrm{T}$ ( $\mathrm{T}$ ext) was always under comfort, from $8^{\circ} \mathrm{C}$, to $14^{\circ} \mathrm{C}$.

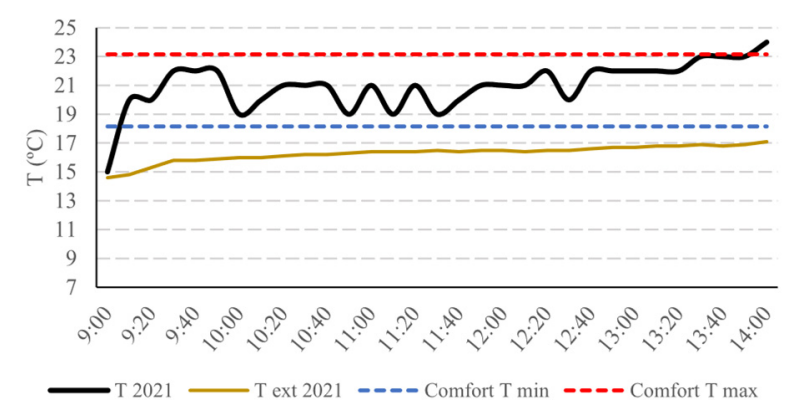

Figure 10. $\mathrm{T}^{\circ} \mathrm{C}$ in a typical winter day, 26th January 2021, compared with adaptative ASHRAE comfort range

In 2021, see in Figure 10, at 09:00 the T was $15^{\circ} \mathrm{C}$, but it rose fast until $22^{\circ} \mathrm{C}$ at 09:30. From 09:30 to 13:50 it was maintained within the comfort ranges, between 19 and 22 ${ }^{\circ} \mathrm{C}$. On the contrary $\mathrm{T}$ ext was steadily raising from $15^{\circ} \mathrm{C}$ at 09:00 to $17.00^{\circ} \mathrm{C}$ at 14:00, which was close to the lower comfort range.

In Table 1 a summary of $T$ from both scenarios can be seen with hourly and average data. Additionally, the variation from $\mathrm{T}$ and $\mathrm{T}$ ext is presented for both scenarios. In 2018 , the variation between $\mathrm{T}$ and $\mathrm{T}$ ext was $8.32^{\circ} \mathrm{C}$, whilst in 2021 , it was $4.12^{\circ} \mathrm{C}$.

Finally, when $\mathrm{CO}_{2}$, and $\mathrm{T}$, are considered together, the 2018 scenario was out of comfort for all the period from 09:00 to 14:00, whilst the 2021 scenario was under comfort from $09: 10$ to $13: 50$.
Table1. T deviation between scenarios 2018 and 2021 .

\begin{tabular}{|c|c|c|c|c|c|c|c|}
\hline & 09.00 & 10.00 & 11.00 & 12.00 & 13.00 & 14.00 & Aver. \\
\hline \multicolumn{8}{|c|}{$\mathbf{2 0 1 8}$} \\
\hline T & 18.24 & 18.24 & 19.56 & 19.81 & 19.78 & 20.37 & 19.37 \\
\hline T ext. & 8.20 & 9.00 & 10.60 & 12.60 & 12.50 & 13.20 & 11.02 \\
\hline T-Text & 10.04 & 9.26 & 8.96 & 7.21 & 7.28 & 7.17 & 8.32 \\
\hline \multicolumn{8}{|c|}{$\mathbf{2 0 1 9}$} \\
\hline T & 15.00 & 15.00 & 19.00 & 21.00 & 21.00 & 22.00 & 24.00 \\
\hline T ext. & 14.60 & 14.60 & 16.00 & 16.40 & 16.50 & 16.70 & 17.10 \\
\hline T-Text & 0.40 & 0.40 & 3.00 & 4.60 & 4.50 & 5.30 & 6.90 \\
\hline
\end{tabular}

\section{Discussion}

Materials and Methods proposed in Section 2 have been adequate for the purpose of this research. However, the EGVOC-165 Air quality Monitor should be replaced for another system to allow more precision in $\mathrm{T}$ data necessary for comfort calculations.

The results shown in Section 3, describe the improvement on air quality from scenario 2018 to 2021, but with some considerations. According to Figure 7 and Figure 8 , the concentration of $\mathrm{CO}_{2}$ has been drastically reduced from a range between $1200 \mathrm{ppm}$ to $2000 \mathrm{ppm}$, to less than $600 \mathrm{ppm}$. This is less than the $800 \mathrm{ppm} \mathrm{CO}_{2}$ concentration suggested by the authorities [14]. Therefore, the result of the suggested ventilation protocol has demonstrated its adequacy to reduce the Covid-19 airborne infection risk. On the contrary, the excess of uncontrolled natural ventilation is producing fast variations in $\mathrm{T}$, and it may have also provided an increase in heating energy demand. According to Figure 9 and Figure 10 both scenarios provide indoor $\mathrm{T}$ between comfort ranges during most of the time, except at 09:10, when children get into the classroom and the space needs some time to achieve a steady state situation.

If $\mathrm{T}$ data are compared only from 10:00, some details must be described: In 2018, the T in Figure 9 shows slight variations between $18.24{ }^{\circ} \mathrm{C}$ to $20.37^{\circ} \mathrm{C}$, whilst in 2021 the $\mathrm{T}$ in Figure 10 shows higher variation in both directions between 19.00 to 24.00 . Unfortunately, T data cannot be solely discussed because $\mathrm{T}$ ext is quite different in the scenarios. As described in Table 3.1, the average $\mathrm{T}$ is quite similar in both cases with only $0.96^{\circ} \mathrm{C}$ difference, but $\mathrm{T}$ ext is $5.22^{\circ} \mathrm{C}$ higher in 2021 . Additionally, the variation between $\mathrm{T}$ and $\mathrm{T}$ ext is $4.20^{\circ} \mathrm{C}$ lower in 2021 . Therefore, to provide a more precise comparison between ventilation scenarios, it would be necessary to repeat the experiment in a winter day with similar conditions to those in 2018. There would probably be more difficulties to maintain $\mathrm{T}$ between the ASHRAE T comfort ranges [20].

Heating energy demand has not been considered in this research to be focused on comfort, but according to the comments from the management staff of the school, the heating system is obviously working more time at a higher rate in 2021 than it did in 2018. Therefore, the energy demand should be higher even with less indoor $\mathrm{T}$.

To increase the performance of the building, some improvements could be done to the ventilation protocol. Openings can be reduced until the $\mathrm{CO}_{2}$ concentration rise to $800 \mathrm{ppm}$. Mechanical ventilation with heat recovery 
and high efficiency filters can replace natural ventilation [5]. Air exhaust should be considered upwards over the ceiling to avoid indoor contamination [10]. Additionally, results can be affected by the influence of windows, the close presence of children and their movement, the existence of mask protection protocols and the effect of air gusts into the classroom, among others. Because of that, Additional monitoring devices could be installed in different positions and heights to have a complete description about the air displacement [22].

\section{Conclusion}

This research has demonstrated the adequacy of natural ventilation as an effective method to reduce $\mathrm{CO}_{2}$ concentration, which is associate in the Covid-19 airborne infection risk.

However, this seems to provide a negative effect on thermal comfort and heating energy demand. Therefore, alternative ventilation methods should be considered to maintain the air quality and ventilation effectiveness, but also comfort and energy performance of the buildings. These alternative methods could be based on two different strategies:

- An improvement version of the natural ventilation protocol which can provide real time evaluation of both, weather conditions and indoor air quality, to adjust the natural ventilation protocol.

- An additional introduction of mechanical ventilation systems with high efficiency filters to maintain the proper air quality levels and heat recovery units to keep $\mathrm{T}$ within comfort ranges, but with less heating and cooling energy demand.

\section{Acknowledgments}

The authors wish to acknowledge the collaboration of the school anonymous staff at the data gathering.

\section{References}

1. A. S. Cordero, S. G. Melgar, and J. M. A. Márquez, "Green building rating systems and the new framework level(s): A critical review of sustainability certification within Europe," Energies, vol. 13, no. 1, pp. 1-25, 2019.

2. M. M. Andamon, P. Rajagopalan, J. Woo, and R. Huang, "An investigation of indoor air quality in school classrooms in Victoria, Australia," Proc. Int. Conf. Archit. Sci. Assoc., vol. 2019-Novem, pp. 497506, 2019.

3. G. de Gennaro et al., "Indoor air quality in schools," Environ. Chem. Lett., vol. 12, no. 4, pp. 467-482, 2014.

4. Plataforma de Edificación Passivhaus and Universidad de Burgos, "Proyecto de monitorización de colegios. Estudio completo e informe de conclusiones." pp. 1-261, 2020.
5. S. G. Melgar, M. Á. Martínez Bohórquez, and J. M. Andújar Márquez, "Uhumebr: Energy refurbishment of existing buildings in subtropical climates to become minimum energy buildings," Energies, vol. 13 , no. 5, 2020.

6. T. D. Tran et al., "Assessment of air quality in school environments in Hanoi, Vietnam: A focus on masssize distribution and elemental composition of indoor-outdoor ultrafine/fine/coarse particles," Atmosphere (Basel)., vol. 11, no. 5, 2020.

7. L. Stabile, M. Dell'Isola, A. Russi, A. Massimo, and G. Buonanno, "The effect of natural ventilation strategy on indoor air quality in schools," Sci. Total Environ., vol. 595, pp. 894-902, 2017.

8. L. Zhang et al., "Characteristics of air pollutants inside and outside a primary school classroom in Beijing and respiratory health impact on children," Environ. Pollut., vol. 255, 2019.

9. T. Salthammer et al., "Children's well-being at schools: Impact of climatic conditions and air pollution," Environ. Int., vol. 94, pp. 196-210, 2016.

10. L. Morawska and D. K. Milton, "It Is Time to Address Airborne Transmission of Coronavirus Disease 2019 (COVID-19)," Clin. Infect. Dis., vol. 71, no. 9, pp. 2311-2313, 2020.

11. A. L. Zhang, Y. Wang, and M. J. Molina, "Erratum: Identifying airborne transmission as the dominant route for the spread of COVID-19 (Proceedings of the National Academy of Sciences of the United States of America (2020) 117 (14857-14863) DOI: 10.1073/pnas.2009637117),"Proc. Natl. Acad. Sci. U. S. A., vol. 117, no. 41, pp. 25942-25943, 2020.

12. Z. Peng and J. L. Jimenez, "Exhaled CO2 as COVID19 infection risk proxy for different indoor environments and activities," medRxiv, pp. 1-9, 2020.

13. V. and A. C. A. Heating, Federation of Eropean Heating, "REHVA COVID-19 guidance document: How to operate HVAC andother building servicesystems to prevent thespread of the coronavirus(SARS-CoV-2) disease(COVID-19) in workplaces," 2020.

14. Ministerio de Sanidad Gobierno de España, "Medidas de prevención, higiene y promoción de 1 salud frente a COVID-19 para centros educativos en el curso 2020-2021," vol. 119, no. 3, pp. 670-673, 2020.

15. Ministerio de Sanidad, "Sistema de climatización de edificios y locales para la prevención de la propagación del SARS-CoV-2,” p. 15, 2020.

16. F. Jomehzadeh et al., "A review on windcatcher for passive cooling and natural ventilation in buildings, Part 1: Indoor air quality and thermal comfort assessment," Renew. Sustain. Energy Rev., vol. 70, no. December 2016, pp. 736-756, 2017.

17. S. G. Melgar, M. Á. M. Bohórquez, and J. M. A. Márquez, "UhuMEB: Design, construction, and management methodology of minimum energy buildings in subtropical climates," Energies, vol. 11, no. $10,2018$. 
18. G. [online] Maps, "Colegio Sor Angela de la Cruz," 2021. [Online]. Available:

https://www.google.es/maps/@37.3989395,-

5.9836181,253m/data=!3m1!1e3. [Accessed: 25-

Feb-2021].

19. W. underground S. Network, "La Barqueta weather station." [Online]. Available: https://www.wunderground.com/dashboard/pws/ISE VIL38. [Accessed: 26-Feb-2021].

20. The American Society of Heating, Refrigerating and Air-Conditioning Engineers, "ANSI/ ASHRAE Standard 55-2013. Thermal Environmental Conditions for Human Occupancy.” New York, 2010.

21. The American Society of Heating, Refrigerating and Air-Conditioning Engineers, "ANSI/ASHRAE Standard 62.1-2019. Ventilation for Acceptable Indoor Air Quality.” Atlanta, 2019.

22. R. K. Bhagat, M. S. Davies Wykes, S. B. Dalziel, and P. F. Linden, "Effects of ventilation on the indoor spread of COVID-19," J. Fluid Mech., vol. 903, 2020. 